\title{
Special Considerations and Reporting among Crime Victims in Lagos: A Qualitative Study DOI: 10.36108/NJSA/6102/14(0280)
}

\author{
Johnson O. Ayodele ${ }^{1}$ \\ Adeyinka A. Aderinto ${ }^{2}$ \\ ${ }^{1}$ Department of Sociology \\ Lagos State University \\ Lagos, Nigeria \\ ${ }^{2}$ Department of Sociology \\ University of Ibadan \\ Ibadan, Nigeria
}

\begin{abstract}
It is commonly assumed that victims' reporting decision making is contingent upon some special normative and contextual considerations. This study examines the effects of these special considerations on crime reporting practices among victims in Lagos, Nigeria, using the qualitative method. The findings indicate that some special considerations anchored on cultural indices of stigmatization, stereotypes, taboos, tenderness of age, and gender are critical to victims' decision-making choices for reporting in the study area. Consequently, it is suggested that government should use public enlightenment to make rational than normative thoughts steer reporting among victims for public safety in Lagos, Nigeria.
\end{abstract}

Keywords: Reporting practices, stigmatization, public enlightenment, public safety

\section{Introduction}

Everywhere in the world, peculiar cultural conditions define the factor that people will recognize as a special consideration for reporting. Victims in societies with past colonial influences may hinge a bulk of their considerations for reporting or non-reporting on rational than normative thoughts. Often, issues emanating from the individual, the police and community context constitute special considerations for victims' reporting choices. The need to be well integrated into a community's mainstream, protect the personal safety or avoid interfering unduly with the collective wisdom may constitute special considerations against which a victim may not act in the context of reporting. This paper aims at improving understanding of these special considerations which underlie victims' crime reporting practices in Lagos, Nigeria. While the police encourage citizens to report crimes to update crime statistics, special considerations determine the proportion of the criminal acts which victims will readily report to the police in Lagos, Nigeria. The victims report some and avoid reporting a greater proportion, in spite of the implications of their actions for the health and safety of community residents. It is against this background that the study examines the following questions: (i) What are the special 
considerations that influence victims' reporting practices? (ii) How do these considerations influence victims' reporting practices? (iii) How can the special considerations improve crime control and public safety in the study area?

\section{Literature Review}

Previous studies have noted that victims have different considerations that play a role in their decision-making (Felson, Messner \& Hoskin, 2002). In this regard, Goudriaan, Lynch \& Nieuwbeerta (2004) presented a two-dimensional framework that distinguishes between key influences on crime reporting decisions to provide a comprehensive model for understanding why individuals choose to report (or not report) crimes. The first aspect of this framework differentiates "situational" from "contextual" influences on reporting behaviour. Situational influences exclusively imply the "immediate crime scene or the face-to-face interaction between the victim and the offender" (Goudriaan et al., 2004: 936). Situational pressures include such phases of the crime as whether the victim was hurt, whether the offender was carrying weapons, the presence of witnesses at the scene, and the physical location of an incident (e.g., at a convenience store or home). Examples of individuals capable of exerting influence on reporting behaviours - even when not physically present at the time of an incident - consist of those with intimate personal ties such as family members, spiritual leaders, and close friends. In some regards, the subtle influence which these significant others exert on the decision-making process constitutes special considerations for victims, especially in traditional societies.

The two-dimensional framework for understanding crime reporting behaviours of Goudriaan et al. (2004) has the second aspect. This other half distinguishes those reporting decisions reached through rational cognitive thought from those that purely reflect one's normative views. The basis of the first or "rational" framework that is reporting decisions are reached through individual cost-benefit analyses aimed at determining whether or not it is worth it to report a crime (Skogan, 1976, 1984). According to this model of decisionmaking, crime is reported only when the benefits of reporting (e.g., recovery of property, reduction in vulnerability to future victimization) outweigh the costs of doing so (e.g. investments of time and effort, potential for retaliation). One key element that shapes the outcome of this cost-benefit analysis is the extent to which the offender harmed an individual as a result of a criminal victimization. Incidents involving relatively more harm, such as those in which the victim was injured or financial loss was great - are more likely to be reported because individuals involved in such incidents perceive the benefits of reporting to be higher than would be the case for less serious incidents. The extent of injury or loss, in this regard, constitutes a special consideration for reporting.

Crime reports that represent normative responses, on the other hand, are not based upon this rational cognitive process. Rather, these types of reporting decisions reflect individuals' normative views or the normative context of their 
social environments. For instance, citizens who believe that it is their duty to report a crime are likely to report even the most trivial of crimes. When individuals choose to report these types of crime, their behaviour is not the result of a cost-benefit analysis, per se, but rather it is reflective of their normative views regarding the importance of crime reporting. For this category of individuals, the desire to show patriotism is their special consideration for reporting. Other examples of norms that are likely to constitute special consideration for reporting include the police not caring about individuals; one preferring to deal with the crime event oneself and a particular crime event is not a matter in which the police would be interested (Goudriaan et al., 2004).

In highly developed societies, survey results show that substantial numbers of women whose experiences can be categorised as rape according to legal parameters do not, perhaps due to special consideration, classify themselves as rape victims, and even those who describe an incident as sexual assault hesitate to define it as a crime (Fisher, Cullen, \& Turner, 2000; Myhill \& Allen, 2002). The above probably falls under the category of criminal acts that do not deserve reporting because of the special-consideration-status which victims give them. It is therefore not surprising that fear of reprisal is a special consideration why some victims decide not to report a crime to the police especially in cases of violent offenses (CBS, 2010; Singer, 1988). In the Netherlands, approximately $35 \%$ of victims report crimes while the willingness to report is especially low for sexual assault (7\%) probably on account of special considerations and high for burglary (87\%) (CBS, 2010). Therefore, variations as indicated by reporting rates for property crimes which range between 38\% (Portugal) and 65\% (Denmark), with an average of 56\% and reporting rates for violent offences which vary from 25\% (Switzerland) to $43 \%$ (Australia), with an average of 39\% (Goudriaan, Lynch \& Nieuwbeerta, 2004), further reinforce the influence of the victims' special consideration for reporting or not reporting. But in Nigeria, only a minority of victims reported crimes to the police, $30 \%$ in 2005 and $11 \%$ in 2006 (Alemika, Igbo \& Nnorom, 2006). Numerous considerations defined as special by individual victims often determine the very low global rate of crime reporting to the police.

For example, if the victim knows the offender well, the chance that the victim fears retribution by the offender after reporting the incident to the police or an alternative authority will be higher than if the offender is unknown (Bachman, 1993; Felson, Messner \& Hoskin, 1999, 2002; Gottfredson \& Gottfredson, 1988; Singer, 1988). In the case of a known offender the probability that the victim decides that it is a private matter in the context of special consideration, and the situation should be resolved privately is higher than when the offender is unknown (Felson et al., 2002). However, emotions such as compassion, anger, and indignation all have powerful effects on how people make decisions about whether to act or remain quiescent (Penney, 2006), especially regarding who reports what crime in almost every society. 
The ways in which situational, contextual, rational and normative influences interact with one another to influence reporting behaviours of victims represents one unique value of the framework which Goudriaan et al. (2004) presented in their illustration. Thus, "any situation or social context in which a crime occurs offers different rational and normative considerations that can influence the decision to report a crime" (Goudriaan et al., 2004: 937), is often based on a special consideration. The concern for special consideration is of particular interest to the present study in the aspect of how social context specifically the influence of the cultural context and the extent of the network of relationships of victims that are involved often influence their perceptions of the costs and benefits of reporting. Also, their normative views regarding the act of reporting a crime in some ways make the factors constitute special considerations.

Worried about the issues that predispose residents of Lagos to a high rate of criminal victimization with a disproportionate level of reporting, analysts have pointed at a poor criminal justice system (Yishau, 2005). Olonishakin (2008) identified corrupt socio-economic and political institutions. Even, Ologun (2010) reported that Onovo, a former Inspector General of Nigeria Police, acknowledged that some police officers were aiding and abetting criminals. All the preceding considerations do not exhaustively explain the disproportional relations of crime events with the reporting practices of victims in Lagos, Nigeria. Persuasive as these correlates may seem, they neglect the importance of usually undisclosed special considerations that underlie the report-decision making among victims in Lagos. Thus, investigating the nexus between victimization and victims' special considerations that inform their reporting practices is important in bridging the identified gap in knowledge.

\section{Theoretical Framework}

The study adopted Weberian social action theory. It found the theory suitable to explain the problem of victims' special considerations in the context of their reporting practices for two reasons. First, it has a better capacity to capture the subjective explanations involved in the crime reporting commitments of community residents. In their construction of meaning, non-reporting that is the outcome of special consideration could be interpreted to be objectively unpatriotic. Subjectively, however, non-reporting could be contextually functional for the victim, the offender and the whole community. Second, it relates victims to offenders, and the contextual situations, cognizant of the crime reporter's shared values, beliefs, and norms. 'What distinguish human behaviour from others are the connections and patterns whose course is understandably explicable' (Weber, 1922: 403-404). It is within the background of interconnections arising from human relations that the need for special considerations in choice making between reporting and non-reporting of crime emerges.

As 'a science which attempts the interpretive understanding of social action to arrive at a causal explanation of its course and effects' (Weber, 1947: 
88), a sociological investigation of victims' special considerations which drive their reporting practices has to be predicated on Weberian social action theory. Often, special considerations become desirable and inevitable explanatory variables to determine the urgency and necessity of the role expectation of the network of relations that binds the reporter (victim), the reported (offender) and public safety (community). Through the instrumentality of culture, socialization of children draws due attention to the environmental realities to which every worthy member of the community must be loyal. In this connection, Weber considers two elements as mandatory requirements of social action. The first, in this context, is the attachment of a subjective meaning to reporting and non-reporting actions. The second is the orientation of the acting person (reporter or non-reporter) to another individual (or other individuals). Social action, in the context of crime reporting practices, involves reporting an offense, its non-reporting or indifference to it, which often occurs subjectively as the crime reporter attaches a contextually satisfying meaning to his/her crime reporting action. Here, non-reporting is nonetheless a social action.

Most victims of crime do not report their experiences of crime. Theoretically, such inactivity is brought into being as a result of a subjective interrogation of the subject matter of crime, offender, victim and overall social order on the platform of special considerations for crime reporting decision making. Furthermore, a non-reporting activity may be oriented to the past, present, or expected future behaviour of others. Hence, non-reporting may be a-special-consideration-induced reaction to a past criminal invasion, defence against the present, or used as a means of protection against future attack. The others, in this regard, may be individual persons, who may or may not be known to the non-reporter but comes under the ambit of special consideration. It is also possible that others may constitute an indefinite plurality and may be entirely unknown as individuals (Weber, 1947).

\section{Data and Methods}

The study was conducted in Lagos State, which is located in the South-West Geo-political zone of Nigeria. Lagos is Nigeria and West Africa's financial, commercial and industrial capital (Arthur-Worrey \& Chukwuma, 2011). Since Lagos city is the largest and most dynamic city of Nigeria, the state is the socio-cultural melting pot for Nigerians of all ethnicities from across the country and non-Nigerians from elsewhere in Africa and the rest of the world (Federal Health International, 2000). Lagos is the economic nucleus of Nigeria and a wealthy state relative to others in the country; its gross domestic product is among Nigeria's highest, at more than US \$235.9 billion (World Bank, 2011). Though, more than a third of the residents of the state consider themselves 'non-poor', against the national average of $25 \%$, and the Human Poverty Index for Lagos is $14.5 \%$, compared with $32.3 \%$ for Nigeria as a 
whole. Generally, Lagos residents have access to better services than elsewhere in the country: over $60 \%$ has access to improved water and nearly all residents have access to electricity (UNDP, 2009), even in its dysfunctional state, but not everybody has beneficial access to the criminal justice systems. The above makes victims develop diverse special considerations that motivate them to report or not report criminal acts.

The presence of all sorts of people as residents of Lagos provides two diametrically conflicting even if interesting social classes - the well protected and those who are not well protected against victimization. Both classes have potentials for crime commission and crime reporting at different rates as may be triggered by their special considerations. As a result of the preceding account, nearly daily, some citizens commit different kinds of criminal acts (Sofola, 2002), which often range from relatively unknown crimes such as drug abuse, smuggling, and advance fee fraud (Igbo, 2003), to corruption and squandering of public funds (Njoku, 2003). The delinquency and criminal behaviours are common phenomena in the communities of Lagos, and the high rate of occurrence in recent time is of greater concern to the society.

The study population comprised all citizens who were 18 years or older and resident in Lagos for a period not less than twelve calendar months as at the time of the commencement of the study. This decision was taken on the assumption that individuals in that category were more likely to be knowledgeable about household members' decision-making process involved in reporting in the communities of Lagos. Similarly, they were expected to be well informed about the available institutions of and framework for reporting system in the community. Also, the study covered selected crime victims, traditional rulers, religious leaders, the chairmen of landlord associations, crime police officers, chairmen of village/town associations, and family members of victims in Lagos. The present study used purposive sampling to select its participants. The researcher did case studies with ten victims of brutal violent crimes. It conducted the in-depth interviews, key informant interviews and case studies in both English and Yoruba. During the interview exercises, data were recorded using hand written notes and tape recorders.

The majority of the Social Science studies have a direct bearing on real people in situations that are not simulated to agree with practices in laboratories by scholars in pure sciences. This situation raises ethical questions regarding the link between the researcher and the participants. The researcher took into consideration the participants and communities' right to participation in the study. He sought and got the consent of chiefs and other participants. Therefore, the participants had clear information about the purpose of the study. The researcher protected the identities and views of the crime victims and other participants. He treated the community members politely and with considerable humility. He ensured that they were relaxed and did not compel them to do or say what they ordinarily did not want to do or say throughout the conduct of this study. He protected the participants against any harm and they 
explicitly got information about their right to withdraw from the study even after signing the consent forms.

The researcher conducted in-depth interview with 3 traditional rulers (customary custodians of culture) and 3 religious leaders (heads of different religious denominations) who he purposively selected equally from each of the three Senatorial Districts, 12 key informant interviews conducted with 3 Crime Police Officers, 3 Chairmen of Landlords' Associations and 6 Members of Victims' Family and did 10 case studies with victims of serious crimes, who he also purposively selected to provide data for the study.

\section{Data Analysis}

The method of data analysis involved qualitative approach. The researcher transcribed the tapes from the various in-depth interviews and compared them with field notes from field assistants. Raw data were transcribed, sorted, labeled and structured into themes according to various headings representing the key issues raised in the interviews and discussions using the research objectives and purpose of the study as guides. The analysis involved the categorisation of data collected into the objectives of the study. Moreover, verbatim quotations, ethnographic summaries, and content analysis were used in the narrative to produce a seamless and robust report of the study.

\section{Data Presentation and Discussion}

\section{The Special Considerations that Determine Victims' Crime Reporting Practices}

As the struggle for survival causes community dwellers to prioritize items on which they spend their precious time, different occurrences encroach on the available time to the extent allowed by the people. In consonance with the above logic, previous studies have found that victims have different considerations that can play a role in their reporting decision-making (Felson, Messner, Hoskin, \& Deane, 2002). A male in-depth interview participant, who also was a crime victim, represents the opinion of minority participants. He insisted that the fear of offender revenge cannot deter them from reporting crime to the police when he observed:

I fear no reprisal attack from any criminal. The criminal is not a spirit. The police are paid to maintain public safety. They are doing this well. One Yoruba Maxim has put it so well when it states that 'mi o le wa ku ko le j'oye idile baba re' (he who is frightened by death may never ascend the throne that is rightly due to his/her lineage.) I am aware that most co-victims did not report their experiences because their special reason for doing so was fear of reprisal. For me, I will report any crime that afflicts me because it is my right to do so as a means of not only asserting my personhood in my community but also talking on 
behalf of victims who have mouths but could not use them to express their minds. Criminals who see what attracts them in your possession will victimize and re-victimize you whether you reported your prior experiences to the police or not. Therefore, it is always safer to report criminal events to the police. (Male Crime Victim Lagos Island LGA, October 20, 2012)

In the study area, victims identified the fear of offender revenge as a special consideration that often compels the majority of the participants to shy away from reporting their experiences of crime to the police. This finding contradicts that of Fohring (2012) which established that a public sense of duty, the need to protect the public and see justice done are heightened in more severe cases. Given the atmosphere of public insecurity in the study area, offender revenge is concrete enough to deter victims from reporting criminal acts. Since there is no law criminalizing non-reporting, any community residents, who refuse to report a crime to the police because of special considerations, will not be committing any crime.

In the reporting or not reporting of crime by victims or witnesses, the police have a role to play. If the police do their community policing in ways that command the confidence of the community dwellers, more people will discountenance the concerns that would have formed their special considerations for not reporting and partner with the police to rid their communities of crime. A twenty-one-year-old male victim of crime, who was a case study participant, lamented his prior experience with the police when he was prevented from reporting the crime for which he was a victim:

It was painful that the police did not accept the account of my having been assaulted when I approached the police station four years ago on the account that I was a minor. The police told me to advise my parents to come and report on my behalf. The question that worried my mind was, did my parents suffer the trauma of that crime? In this regard my being an underage at the time the crime occurred, for me, was a special consideration for the police not to recognize my reporting. As a person, I wanted the crime reported.

Beyond the consideration of age as special, in the present study, a significant number of victims held the seriousness of injury or loss as their special considerations for reporting their experiences of crime in anticipation of financial claims, health insurance benefits and securing rewards that are commensurate with the offenders' criminal acts. This finding substantially agrees with an existing finding by Skogan (1984) that crimes tending to produce some form of personal gain (e.g., property crimes) were more likely to be reported to the police, for insurance purposes (Goudriaan, 2006; Tanton \& Jones, 2003). Recognizing that the level of reporting is a measure of community participation in crime prevention and control as well as of public 
confidence in the criminal justice system (Carcarh, 1997), the present study asked participants some questions on how they perceived the criminal justice system as facilitating or obstructing reporting. Most of the participants provided numerous reasons that make the police a special consideration for not reporting. A female victim of online scammers expressed her disappointment at the police when she contacted them, and they bluntly refused to record and even investigate her victimization. She argued:

The police did not mince words in telling me that they were not going to take official notice of my complaints. They accused me of knowing the right thing, but I chose not to comply. At first, I thought it was the usual bribe game that they were trying to associate with reporting. I was calculating how much I should offer when the officer on duty told me rather disappointingly that I should go and tell my husband to come and report on my behalf. I felt highly insulted. I had to walk away from the station. From that time, my sex became my special consideration for not reporting a crime to the police. (Female (IDI) Mushin LGA October 31, 2012)

Furthermore, some participants identified other criminal-justice-systemrelated special considerations and emphasized the cumbersomeness of the judiciary which has institutionalized the come-today-come-tomorrow syndrome as a special consideration for non-reporting for a group of victims. For this reason, most participants considered following up criminal cases to the level of litigation is not only a direct way of providing unmerited additional income for court workers; they strongly feel they should not take their worst attacker to court. The unnecessarily too-long-drawn-out nature of criminal proceedings in Nigeria does not only waste litigants' money, but it will also waste their precious business time and increases their trauma. For this purpose, discouraging court processes are a strong element that constitutes a special consideration for victims' non-reporting practices in the communities of Lagos.

It may seem odd in a country in which women constitute almost half of her population that the police consider women citizens incompetent to report criminal acts to the law enforcement agency, except by proxy. The above is the reality in the communities of Lagos. However, the preceding finding is in agreement with the findings of Bureau of Justice Statistics' (2012) that the percentage of unreported violent victimizations were not reported because of a police-related reason (i.e., the police would not or could not do anything to help) nearly tripled from 2005 to 2010. Furthermore, marital status was one of the special considerations that govern crime-reporting behaviour in the study area. Another female in-depth interview participant argued angrily:

Why should the fact that a woman is married become debility in the context of reporting? Before we married, we could not report 
because of our female gender. When our status changed as a result of maturity, the disqualification intensified. There should be something special that is outside the consideration of biology which disqualifies a non-male victim from reporting crimes in the communities of Lagos. This demeaning treatment is unfair to women! (Female (IDI) Ibeju Lekki LGA October 23, 2012)

The finding of this study is consistent with the work of Berk et al. (1984) and Black's (1976) theories on relational distance, and Rational Choice Theories (Block, 1974; Skogan, 1984), that married women are less likely to contact the police. Being a third world city, many residents of the communities of Lagos still live very traditional lives. Religion still controls a significant proportion of their routine activities. Therefore, religious consideration comes first as a special consideration for most community resident in reporting their victimization to the police. In this regard, another participant, who is a Muslim faithful, recalled how her faith became a special consideration for her not reporting her experience of crime to the police:

On narrating the crime event of how some criminals victimized me to my imam, he quoted copiously from the Quran why I must allow sleeping dogs lie. He told me that whatever happened to me, Allah knows about it before it did. He convinced me that Allah wanted the crime to stop me from being a victim of a more grievous crime. With the intervention of my imam, I gave up the urge to report the case to the police because I preferred Allah's protection than the one the police will offer. (Female (IDI) Ibeju Lekki LGA October 25, 2012)

Some victims saw the problem of uneven provision of social amenities for residents of the different communities making up Lagos by politicians as a special consideration for them not to report their victimization to the police. Some victims, who anchored their exclusion from reporting to the police not because of age or sex but by the distance of their places of residence to the location of the police station argued that government appears to have forgotten some of the community residents who live far away from police stations. It is not reasonable to go out at night especially when there is no electricity to report cases of crime to the police. In the course of doing these, victims face the challenge of being victimized by another new set of assailants because the environment is very unsafe and unprotected.

Reasons considered to be special differ from one person to another in the different locations of Lagos. For a sixty-one-year-old male victim of crime, his special consideration for not reporting crime to the police was his inability to speak the English language. Being an illiterate, he could not explain his mission in English. As a consequence, he swore never to go to the police station again to lodge any complaints. Also, being without concrete property and mechanism for self-protection or means of ensuring target hardening are, 
for most of the participants, who are from the low-income bracket, poverty is their special consideration for not reporting their experiences of crime to the police. In this regard, a male in-depth interview participant explained:

I am from a family background that is committed to the belief that integrity is better than riches. This philosophy holds us down to the lower rungs of the economic ladder of society since we refused to buy into the widespread corruption slogan of ifyou-cannot-beat-them-join-them rat race for self-enrichment. Thus, in spite of our lack of property, one special consideration for our not reporting any criminal attacks we experienced remained our inability to sustain the cost of reporting a crime to the police in Nigeria. (Male Crime Victim Ibeju Lekki LGA October 20, 2012)

The above finding is in agreement with that of the Bureau of Justice Statistics (2006) which noted that low-income persons have higher victimization rates for violent crimes than high-income persons.

The case study in the following box shows how the provision of clues that led the police to apprehend a criminal who is known to the witness could cost the crime reporter his/her life. The uncertainty of protection after reporting and fear of retaliation constitute a significant special consideration for not reporting of crime in the study area because of questionable integrity of the police and the impunity enjoyed by criminals, in the aftermath of crime.

\section{Case study 1}

I am a businessman, Christian, an Ijebu man, married and live in Lagos. I am not the direct victim but a security man was. Since he did not survive the event, I am a secondary victim because the incident touched me and I still find it difficult to believe that what happened to him could occur in a civilised environment such as Lagos. The victim did plumbing work for me on part-time basis. He lived in my neighbourhood. He saw some hoodlums as they killed a security man and victimised a woman. The woman reported to the police. My plumber simply identified some of the criminals as community boys. The police instantly arrested them. Later, after the usual police negotiation that often compromises public safety, the police told the hoodlums that it was my plumber who identified them. Then, the criminals went after my plumber and hacked him to death. Up till today, nothing came after the investigation into the killing of the poor plumber. Therefore the fear of retaliation by hoodlums justifies some residents' unwillingness to report their experiences of crime to the police. It is tragic to know that the police even help criminals to write reports that will incriminate crime reporting victims or witnesses and facilitate the release of criminals, who provided money that causes the police to remain subjective. 
Some participants also identified the presence of cultural structures that provide justice through indigenous framework as a special consideration for their non-reporting of crime to the police in the study area. For the fact that reporting crimes to customary structures are cheaper, faster and community friendlier, most participants believe that approaching the police is an indirect subjection of themselves to unnecessary coercion and extortion. That a victim's cause is righteous does not make the complainant blameless in the judgment of the Nigeria police. For these reasons, the mere presence of these options in the communities of Lagos represents a special consideration for victims. The presence of the preceding structures accounts for their declining rate of reporting of crime to the police. This finding agrees substantially with that of Alemika (2009) that people reported their experiences of criminal attack to different agencies, including non-law enforcement agencies depending on what they perceived as the cost of doing so as well as their individual perception of personal gratification from doing so.

In the present study, most female participants looked at the special consideration that might make them overlook the reporting of offenders who attempted to rape them to the police and identified their prior knowledge of the offenders or the fact of the offenders being members of their family. The female participants were aware that prior knowledge of the offenders could be dangerous to their safety as the victims if they report their experiences to the police. Most of the participants who were victims of rape or attempted rape admitted knowing the men who raped them, in most cases, to avoid being dishonourable persons in their neighbourhoods. The above reasons account for why most women internalized and treated many cases such as these as private affairs. Their reluctance to report rape cases stemmed from the fear that the criminals might return to re-victimize them as a form of retaliation which might jeopardize their chances of getting husbands in their communities in future.

Those who are already married are afraid of stereotypes and stigmatization. The above finding is in agreement with that of the Bureau of Justice Statistics (2012) which found that crimes perpetrated by someone the victim knew well, such as a neighbour, co-worker or teacher, or by a casual acquaintance were more likely to go unreported than crimes committed by a stranger. The finding of the present study is also in tandem with that of Felson et al. (2002) which established that in a case of a known offender, the probability that the victim decides that it is a private matter and the situation should be resolved privately is higher than when the offender is unknown. However, emotions such as compassion, anger, and indignation all have powerful effects on how people make decisions about whether to act or remain quiescent (Penney, 2006), particularly when reporting is stimulated by special consideration regarding who reports what crime in almost every society.

Data in the present study also revealed that participants' ages are a special consideration for not reporting. Findings in the present study established that 
participants whose ages fall within the category of 21 and 30 years, displayed relatively low pattern of crime reporting. Young people have special considerations that justify their crime-reporting apathy. These findings support earlier ones that peer pressure and the amount of guilt that young people hold for engaging in frequent fights, among others, are identified as special considerations for their low reporting rates (Tanton \& Jones, 2003; Skogan, 1994). Exemplifying this, an in-depth interviewee observed:

Conventionally, younger people are adjudged not skillful to report crimes, but we are not well protected against victimization. Nobody can take care of our interests the way we will do. If you defy elders' advice to report a crime that affects your life to the police, the men, and women police will look at you as if you needed additional criteria to qualify for citizenship. The crimes that affect the interest of children are so numerous to be left in the hands of the so-called adults to report by proxy. The proportion of crimes that are not reported on account of age is so significant that makers of policy on security need to recognize the necessity to remove age as a criterion for reporting because the percentage of crimes that violates the interests of children is so high to be ignored. (Male Victim (IDI) Ibeju Lekki LGA,(October 23, 2012)

In some situations, community's social structures manufacture some special consideration for the non-reporting disposition of community residents in the study area. Most community people do not support criminality. If the community enjoins its members to report crimes and at the same time teaches them that won kii t'oju onika mesan kaa (you do not foolhardily do certain things in the presence of the individual whose interest is ultimately likely to be injured). Two critical issues involved here are reporting an individual who commits a criminal act and who may become aware of your 'harmful' act. The above throws up a cultural contradiction. The culture that teaches members not to cover crime up turns round to warn the same members to be cautious about whistle-blowing conduct. From the above, it is clear that reporting a crime in this kind of situation requires the use of native wisdom so as not to earn a bad reputation in the neighbourhood. If a victim reports a crime in a way that is inconsistent with the community people's normative orientation, one may appear to have done well in formal terms, the consequences of his/her actions may be ruinous to his cultural integration and those of his/her network in the foreseeable future because ode a fi fila perin, ojo kan ni iyi re mo (a hunter, who dexterously killed an elephant with a mere cap, has reverence but for only a day.)

To community people, some other special considerations for reporting include the attitude of the criminal justice system. The study participants 
looked at judicial-associated special considerations for not reporting crimes to the police on the ground of inappropriate compensation as well as the denial of victims' rights. Some of the participants lamented why they must report a crime when the state will ultimately take over all the benefits that should accrue to the injured victim? The government, through the instrumentality of the judicial system simply makes victims witnesses in their cases. Most of the participants wait patiently for the day the police will be reformed to relate pleasantly with the people. Also, none of the participants was satisfied with the extortion that goes on at most police stations in the study area. It is an awkward paradox for the police to extort money from distressed victims who have lost their property to criminals or have been mortally injured. If the reasons that led to the victimization of the victims in the various communities of Lagos are critically examined, the inefficiency of the police will stand out like a sore thumb. They were not where they were supposed to be, ensuring community surveillance. In reality, police prefer to protect politicians for an instant payoff. Most people avoid reporting to the police to avoid turning themselves into human ATMs for the insatiable appetite of the police for extortion.

The data in the following case study show that the questionable conduct of the police as the primary custodian of law enforcement could constitute a special consideration for victims' unwillingness to report their experiences of crime.

Box 2: I am a 32 year old Muslim and a driver from southwest Nigeria. It was on a Saturday afternoon, when the police embarked on their reckless arrests. The police arrested me for an unjust reason, detained and charged me to court. The criminals in this instance are the police. Who then is empowered to arrest the police? The crime was reported to a civil rights lawyer, who created a public awareness about my illegal detention for a crime I did not commit. Subsequently, I was granted bail. The event affected my economic and psychological wellbeing. Police brutality to me has further deepened my lack of trust in the agency. The information provided by the police was insignificant. The level of sympathy which the police demonstrated in my case was very poor. To me, the police do not have the bravery to solve crime in my neighbourhood because the level of police loyalty to public safety is ridiculously low. However, my case got to court and I was present. The police were never punished. My court experiences were partially positive. I would have been happier if the presiding judge had indicted the erring police. I suggest that public policy should consider the use of informal crime control alternatives to solve crime in some specific tradition driven areas in future. At the same time, I would have loved a system for getting support that did not involve the police in my community. Nobody provided any form of support for me. I paid the lawyer myself. I learnt someone wanted to support me, but the divisional police officer declined. 


\section{The Influence of Special Considerations on Victims' Crime Reporting Practices}

This section presents the influences which participants said their special considerations exert on their crime reporting practices. Special considerations of victims on reporting have their various influences. For a community to respond to crimes, its members must have anchored their crime reporting decision making on specific concerns. Among this array of concerns, some are special to victims while a few to the survival of the community itself. These motivating factors make some considerations account uniquely for the rhythm of participants' reporting dispositions. Therefore, special considerations of participants for reporting crimes did not put all the participants in two distinct classes of crime reporters and non-reporters. It is instructive to note that making some factors come under special considerations for reporting could make reporting as a patriotic expectation of every citizen especially problematic in traditional communities. In Nigeria, some common indices such as places of residence relative to police stations, age, sex and ethnicity, demonization and commercialization of reporting are significantly relevant to reporting decision making.

There are some participants who believe that special considerations could either facilitate or frustrate reporting. An in-depth interview participant, who was neither here nor there in his attitude to special considerations for reporting reinforced this position when he argued that:

Special consideration is like a sword with two edges. Just as it can facilitate reporting, it can also frustrate it. For example, in our community, incest is a taboo. We do not report incest to the police. Its shame is not only for the perpetrator. It goes beyond to tarnish the image of the family and the overall integrity of the community which may be adjudged as having no far-reaching tradition on issues of morality. Maintaining the good name of the family and community thus becomes a special consideration in the process of crime reporting decision making. Conversely, my community believes that murder is a reportable crime. Anyone who commits the crime of murder must be reported because it is a crime against the gods of our land. Since it is important to the community to see every murderer as an outcast, reporting such an offender is a special consideration for all members of the community so as to remain a norm-compliant member. (Chairman, Landlord Association (IDI) Mushin LGA October 21, 2012)

In some situations, the disposition of the police to the reporters of crime becomes a special consideration for not reporting. A 53-year-old female indepth interview participant, who is a cement dealer, examined the influence of 
the attitudes of the police that constitute a special consideration for residents' non-reporting practices and concluded:

Occupationally, the police are paid to protect the people. Additionally, they are trained to provide confidential coverage and protection to community members who volunteer information for the uncovering of crime and its prevention. However, when police officers, divulge the identities of informants, the police deliberately or inadvertently expose the crime reporters to predictable danger. The influence of this conduct is that most community residents will not partner with the police for crime prevention in Lagos, Nigeria. The above has collateral implications for crime control and public safety in Lagos. (Female (IDI) Lagos Island LGA October 20, 2012)

The cultural exclusion of children from having the capacity to think rationally has been legalized such that some victims in Nigeria do not qualify to report their experiences of crime by age. In Nigeria, victims who are minors do not have the right to report their victimization except they are assisted by some male adults before their complaints can be documented and accorded the rightful status. This provision is archaic. The effects of crime are as painful to the elderly as they are to the young. That police do not tolerate reporting by minors may accentuate the rates of crime which offenders commit against them. For the above reasons, age is not just a special consideration for reporting; it becomes a special consideration for offenders to commit more crime. On the whole, critical crime data, in respect of the excluded population, will elude the overall crime statistics. Furthermore, the security policy makers may not have information to design appropriate public protection plan for the excluded, thinking that all is well with them.

Concerning religion, the intervention of the men of God in the reporting of crime process is more favorable to non-reporting than reporting. It is only in extreme cases that the men of God will abandon counseling for victims of crime and encourage them to report their experiences to the police. Thus, the intervention of men of God in crime reporting by their followers is obstructive of due process. Beyond that, available crime statistics will not reflect the pattern of the victimization which members of the various religious places experience in the community. As a result, the kind of public protection which religious adherents are likely to have will not reflect the extent of their victimization because of the absence of data which accurately indicate the kind of victimization experiences to which they are exposed.

Worried by the neglect of women regarding crime reporting, a 56-year-old female in-depth interview participant lamented loudly whether Nigerians need divine intervention to accord full human dignity to their women so as to realize the implication of their not being maximally encouraged to contribute to national development through crime prevention. A long time after the Beijing conference, Nigeria still has not accorded full human value to her women. 
Since the population of women is almost at par with that of men, the refusal of the police to entertain crime reports from women is like reducing the sources of crime that occur in the community by half. The influence of this on public safety is that half of the population risks living in the perpetual thought of being discriminated against regarding crime-prevention inclusion. Also, rather than approaching the police, the implication of the preclusion of women for public safety and development is that the excluded half of the population may seek self-help measures, look towards the traditional structures of crime control or faith-based institutions for cheaper protection.

In developing societies of the world, the level of infrastructural development informs the kind of factors which the citizens regard as special consideration for reporting. In light of this, a male in-depth interview participant, who is a traditional ruler, sees in the location where a victim is a special consideration when he argues:

Some locations are not within easy reach of the close watch of the law enforcement agencies in certain parts of Lagos. Living in such locations that are far away from the police stations constitutes a special consideration for not reporting for such victims of crime in those communities. As is the case at Ibeju Lekki, if robbers victimize you at night, you have to wait until morning to report. Otherwise, as a victim, one might be running a risk of a more intense victimization, if one is foolhardy to approach the police at night. The exercise of caution by some victims, who live far away from the police stations in avoiding further victimizations, may inadvertently exclude their experiences of crime from being reported and captured in the crime statistics. Consequently, security policy makers may erroneously believe that residents in areas where reports of crime are not received are living in relative safety. (Male Traditional Ruler (IDI) Ibeju Lekki LGA October 24, 2012)

In some cases when victims do not have western education, communication at the police stations becomes a barrier. In this situation, non-reporting of individuals who lack the western education has some concrete implications. The police should make provision for illiterate victims to accommodate their complaints. The implication of the crime statistics not capturing the experiences of victims who are not educated because of the language barrier is that policy maker on security may not skilfully provide for illiterate victims of crime in the communities of Lagos since there are no indicators suggesting that they experience victimization. Moreover, there are some instances when infrastructural breakdown deprives some communities of certain basic services that make reporting death-defying. An in-depth interview participant, who feels strongly about the impact of the failure of government services remarked: 
Availability of phones in these days of sophisticated information technology explosion is expected to be a crime prevention resource. However, concrete as information technology resources are constant power outages make instant online reporting to the police at night unrealistic. Consequently, without inhibition, criminals will operate to endanger public safety. (Male (IDI) Mushin LGA October 23, 2012)

According to some participants, some police officers extort money from victims of crime who had managed to suppress their agonies to seek help that will make them overcome their trauma. To the extent that majority of community people remain low income earning families, they have no insurable property for which they could be compensated, in the event of theft, upon reporting. They nursed their injuries, using traditional healers, in the aftermath of crime. It is, however, instructive to note here that traditional healers do not require the police report to attend to the victims of crime. Therefore, not capturing reports of crime by the poor excludes the extent of the experiences of victimization which the lowly placed people, usually the most victimized in the developing societies, suffer in the communities of Lagos. It is perhaps useful to observe that the experiences of victims in traditional environments differ significantly from those of their counterparts in developed settings. It is not strange to participants in the study that crime reporting is sometimes demonized. Giving testimonies that misconceptions arising from deliberate demonization of crime reporting as a special consideration for not reporting to the police imperil community safety, a male in-depth interview participant observed:

Before I became enlightened about the gains of reporting crimes to the police, socialization made me see reporting as ritualized and demonized. I was thumb screwed into believing that reporting will expose traditional interaction, integration, indigenous secrets to aliens, and trivialize the established conflict resolution mechanisms. One of the crime-reporting discouraging normative sayings is that a kii de lati ile ejo wa d'ore (litigants don't become friends in the aftermath of formal verdicts). (Male Crime Victim (IDI) Lagos Island LGA October 20, 2012)

On the implications of a victim's knowledge of the offender being a special consideration for reporting of crime to the police, whenever community residents treated knowledge of the offender as a special consideration for reporting, they often became a lot more emotional and subjective. They lost the focus of the substance of the offense and dwelt primarily on sentiments. For example, a man raped his uncle's daughter. Members of the family could not report the crime to the police to keep family relations intact, but the trauma may never leave the victim forever. From the above, it became clearer to 
community members that placing an undue premium on the knowledge of the offender more than the crime is likely to shift emphasis from the substance to the pursuit of a mere shadow. The above can make criminal issues seem noncriminal and the victim wallow in self-pity eternally. As a result, no matter the relationship of a criminal to his/her victim, public policy should encourage the victim to report and ensure that the offender is adequately rewarded for his/her wrongdoing.

A key informant interview participant, who also is a police officer, considered the illegality of a non-law enforcement structure which forcibly arrests, tries, and passes a judgment of death on a suspect as a special consideration for some victims' non-reporting practices. He identified the implications of the diversion of reporting by some community residents to this alternative structure:

When a community member who has a legitimate complaint against his or her assailant takes the report to the oro (a deity) on the presumption that the offender is a witch, this has established a special normative consideration for not reporting to the police. The oro usually uses force to effect the arrest of the supposed witch or the evil doer in the community. Nobody in the vicinity will ever dare to report such a reckless arrest of a witch by the oro. It is often assumed that the crime of arresting and killing someone suspected to be guilty of witchcraft by oro is justified, especially among the Yoruba people of south-western Nigeria because the oro acts in the public interest. The implication of non-reporting in this instance for social order is the denial of the fundamental human rights of the supposed witch to access justice through the due process. As a special consideration for not reporting, this normative anarchy encourages extra-judicial trial and murder. (Male Police (KII) Mushin LGA October 20, 2012)

Making Special Considerations Improve Victims' Crime Reporting Practices This section presents the measures which participants suggested towards engineering a better regime of crime prevention through crime reporting practices using the resources of special considerations to improve public safety in the study area. There are special considerations for reporting which need to be improved by public education and provisions. Similarly, special considerations for non-reporting which require reviewing, refining or discarding were identified. Participants suggested appropriate remedial interventions. In this regard, a female key informant interview participant noted:

If a relation is a criminal, that fact should not stop a victim from reporting his/her criminal acts to the police. In the West, a father 
could report his son to the police if his movement becomes suspicious. It was the prior report of Abdulthalib's father to the American government that set him free from complications in his son's bomb involvement in the United States. It is always in the interest of personal and community safety that a witness reports all crimes, regardless of the relationship of the offender to the victim or witness. (Mother of a Victim (KII) Ibeju Lekki LGA October 15, 2012)

Participants looked at how the normative orientation of community people as a special consideration for reporting could be used to improve reporting decision making for community safety. They observed that doing things normatively is one of the human traits that underscore the presence and significance of culture. They subscribed to the idea that every useful culture condemns criminality and its users pull resources together to compensate victims. One way by which the participants believe that collective condemnation could be made to have a vivid expression in every ordered community is through the reporting of the occurrence of crime to the police with an expectation to ultimately lead to the elimination of the culture of impunity among criminals. Participants acknowledged that any norm, therefore, that frustrates crime reporting is against public safety and development. Such norm should be discarded for progress to develop a firm root in their communities. It is in this direction that they wanted the government to criminalize the arrest of perceived criminals by oro (a local deity) because its adherents are not above the laws of the community. Similarly, the participants wanted public policy to encourage the oro as a cultural property of the people to re-evolve, identify criminals, apprehend and hand them over to the police for formal processing. Its adherents can, however, monitor how the police follow the due process so that such criminals do not come back to the community unprocessed to threaten the peace.

A key informant interview participant also the wife of a crime victim examined the influence of gender issues as special considerations on crime reporting decision-making and noted:

Although the sentiment that men are the traditional heads of the family still subsists in most parts of the study area, being partly traditional, this should not be used as a special consideration to put women at a disadvantage in the context of crime reporting. The contemporary understanding should follow the logic in Yoruba saying that if a man notices a snake and a woman kills it; what is important is that the snake does not escape to do havoc some other day. In the same vein, if a man witnesses a crime and a woman reports it, what is of prime importance to collective living is that the criminal is apprehended and adequately rewarded for his/her misdeeds on his or her arrest. Therefore, gender should not be an issue in reporting a crime to the police. 


\section{(Wife of a Victim (KII) Lagos Island LGA October 24, 2012)}

The participants also subjected the question of the age of victim as a special consideration for reporting to a critical examination. The participants observed that there is a need for a collective thought on the improvement of the non-violent response of the community dwellers to crime. They agreed that it is possible for an individual's chronological age to confer experience-induced wisdom on a community resident; it is also possible that it might not have any significant impact whatsoever. In the latter case, a younger person may demonstrate a more resourceful crime reporting wisdom than an older community member. It is on this premise that using age as a special consideration for who reports a crime appears counterintuitive. Culture should encourage whoever has a complaint about a crime to report to the police, no matter the age.

Most of the participants who argued as child's right activists argued that there is a need to include every member of the communities in the provision of crime information to the police. In this connection, the participant concluded that the police are not as useless and unreliable as community residents try to portray them. Granted that successive governments have not shown adequate commitment to the equipment and remuneration of the personnel of the agency, participants are sure that if the government becomes more caring, retools and retrains the police to have skills that can intimidate contemporary criminals, public confidence in the police will become a special consideration for community residents to respond positively and non-violently to criminality with lots of enthusiasm.

An in-depth interview participant, who also is an Islamic clergy, thought about how special considerations based on personal characteristics can become useful in promoting crime reporting practices for community safety. He added: Many potential crime reporters shy away from reporting because of the attendant costs, especially now that politicians have looted public treasury, leaving the poor members of the public to suffer without any hope, in the foreseeable future, of recovery from poverty. Therefore, I suggest that public policy should liberalize crime reporting procedure such that it does not inflict any additional cost on the victim who volunteers to report any crime event. Moreover, as a temporary measure, crime reporting training should be made a compulsory part of orientation for intending couples to improve their reporting capacities while as a long-term measure, reporting values should be integrated into school curricula and taught to learners from the primary through secondary to tertiary stages of education. (Male (IDI) Ibeju Lekki LGA October 15, 2012) 
The social action theory of Max Weber has helped to establish that the subjective judgment of victims regarding what constitute special consideration for reporting is individual specific. Whichever way the decision of the victim falls, he or she is demonstrating a social action in so far as his or her decision takes cognizance of other members of the community and orients them in the course. Therefore, the reporting of an offense, its non-reporting or indifference to it, which often occurs subjectively as the crime reporter attaches a contextually satisfying meaning to his/her crime reporting action, each meets the conditions of a social action. Theoretically analyzed, most victims of crime who do not report their experiences of crime do so on a subjective interrogation of the subject matter of crime, offender, victim, and overall social order on the platform of special considerations for crime reporting decision making.

A perfect method of investigating social reality does not exist. All research methods in use in the social sciences, notably quantitative or qualitative, have their inherent weaknesses. Just as it is with other research methods, the methods that the researcher used in the present study have their weaknesses and limitations. Most participants in the study objected to the use of electronic recorders. Victims of serious crimes were unwilling to disclose their victimization experiences in a face- to-face interview setting, particularly with individuals they did not know before the interview. The above made the exercise a bit more challenging. Moreover, between Monday, October 22 and Wednesday, October 25, 2012, members of the Lagos Traffic Law Task Force arrested motorcycle 'Okada' riders in a bid to enforce compliance with the Lagos traffic law forbidding okada riding in some named roads in Lagos that was then newly passed. Following the exchange of gunshots between the police and hoodlums, who had hijacked the protest, data gathering efforts in most parts of the study sites became unsafe. The panic that followed disrupted data collection and the researcher directed all research assistants to seek safe escape routes to their homes.

Moreover, the intermixture of urban, semi-urban and rural settings for the study created some problems which brought some limitations to the study. Lagos was divided into urban, semi-urban and rural areas to facilitate comparative analyses. On the field, it was discovered that traceable streets exist only in the urban and semi-urban areas. Mostly in Ibeju Lekki, communities were in dominant use, not streets. It took some time, working with educated Ibeju Lekki indigenes to substitute communities for streets effectively before data gathering began. While on the field, research assistants found that most Yoruba participants, especially in semi-urban and rural areas of Lagos did not willingly want to accept that they had been victims of crime. In Yoruba, the meaning of crime is Oran. Thus, a criminal is Odaran. The moment the question is put 'Nje awon odaran ti seyin ni jamba kan tele ri?' (Meaning have you ever been victimized by criminals?)

In the quest of participants to prove their protection against any form of misfortune, they usually responded by answering, in both semi-urban and rural areas of Lagos, that 'Olorun koni jeki nse konge awon odaran ati oran won' 
(I reject criminals and their evil deeds in the name of God.) But further probes into which kind of crime they had experienced caused them to disclose different crimes such as robbery, assault, stealing, rape, etc. This widespread reluctance to provide the exact picture of the participants' victimization experiences constituted a challenge to the study. Also, the biting economic hardship in Nigeria is a potent limitation to the present study. At some points, some participants even requested for gratification on the ground that the time the interviews took from their business hours meant a loss to them, regarding their profit earning calculation. In spite of these limitations, the present study explored the socio-cultural terrain of participants in Lagos communities to glean useful data for policy intervention in victimization in the study site. As a way to push the frontiers of knowledge creation further outwards in this aspect of community life, investigations on special considerations of victims for reporting or non-reporting should be conducted in ethnic communities outside the Yoruba people to see the picture which such considerations present for public safety in other parts of Nigeria.

\section{Conclusion}

The study examined the special considerations of victims which drive their crime reporting responses in the communities of Lagos. It found that some customary evidence account for the crime-reporting behaviour of participants. The study has shown that contextual, police-associated and individual victims' special considerations influence crime reporting. Similarly, the presence of traditional structures as alternatives to formal social control is one special consideration that diverts a significant proportion of crime reports away from the police in the study area. Nevertheless, the underlying concerns of victims regarding whether to report a crime or not, especially when normative and contextual issues are the constraints need to be identified, studied and understood as a credible platform for making public security reforms.

Taking the findings of the present study into consideration, it suggests that:

i. Community residents should not recognize offender-victim relationship as a special consideration because it impedes the reporting of relationinduced violence.

ii. Any reporting-impeding norm should be discarded because it encourages the culture of impunity among criminals and waters anarchy in the community.

iii. Disabling women from reporting a crime in the contemporary times, by sex, is counterintuitive.

iv. Using age as a special consideration for who reports a crime is unfair to the members of the excluded population. Therefore, every community member, who has a case to report to the police, should do so without any inhibitions. 
v. For public lack of confidence in the police to stop being a special consideration for not reporting, the police should function ethically.

vi. Public policy should liberalize reporting procedure to enable the poor relate with the police with less emotional pains.

vii. Public policy should make crime-reporting training a compulsory phase in the orientation of intending couples and the values of reporting incorporated into the school curriculum at all levels of education.

\section{References}

Agnew, R.S. (1985) "Neutralizing the impact of crime," Criminal Justice and Behaviour, 12: 221-39.

Alemika, E. (2009) National Criminal Victimisation and Safety Survey, Summary of Findings Lagos: Cleen Foundation.

Alemika, E., Igbo, E. and Nnorom, C. (2006) Victimization, Safety, and Policing in Nigeria: 2005, Lagos, CLEEN Foundation, Monograph Study, (3): 49.

Black, D. (1984) "Crime as Social control," in Toward a General Theory of Social Control, Selected Problems, ed. D. Black, Academic Press, Orlando. Vol. 2.

Bureau of Justice Statistics (2006) Criminal victimization, 2005. Washington, DC: U.S. Department of Justice.

(2012) Victimizations Not Reported to the Police, 2006-2010. U.S. Department of Justice, Office of Justice Programs. Retrieved on January 03, 2015 from www. OJP.USDOJ.GOV.

Carcach, C. (1999) Reporting Crime to the Police. Australia: Australian Institute of Criminology. No. 68.

CBS (Centraal Bureau voor de Statistiek) (2010) Integrale Veiligheidsmonitor 2010. Landelijke rapportage. Den Haag: CBS.

Felson, R., Messner, S.F., Hoskin, A.W. and Deane, G. (2002) Reasons for Reporting and Not Reporting Domestic Violence to the Police. Criminology, 40(3): 617-650.

Fisher, B.S., Cullen, F.T. and Turner, M.G. (2000) The Sexual Victimization of College Women, National Institute of Justice, Bureau of Justice Statistics, Washington D.C.

Fohring, S. (2010) Crime Type and Community: A Multi-level Investigation of Reporting Behaviour in Scotland. An unpublished Third Year Ph.D. Presentation.

Goudriaan, H. (2006) Reporting Crime. Effects of social context on the decision of victims to notify the police. Unpublished Ph.D. Thesis. Veenendaal: Universal Press.

Goudriaan, H., Lynch, J.P. and Nieuwbeerta, P. (2004) Reporting to the police in western nations: a theoretical analysis of the effects of social context. Justice Quarterly, 21: 933-969. 
Harlow, C.W. (1985) Reporting Crimes to the Police: Bureau of Justice Statistics Special Report NCJ-99432, US Government Printing Office, Washington DC.

Myhill, A. and Allen, J. (2002) Rape and Sexual Assault of Women: The Extent and Nature of the Problem: Findings from the British Crime Survey, Home Office: London.

Penney, R.A. (2006) Interpretation, Meaning, and Worker Solidarity. Social Problems, 53(2): 139-160.

Singer, S. (1988) The fear of reprisal and the failure of victims to report a personal crime Journal of Quantitative Criminology, 4: 289-302.

Skogan, W.G. (1984) "Reporting crimes to the police: The status of world research," Journal of Research in Crime and Delinquency, 21: 113-37.

(1994) Contacts between Police and Public: Findings from the 1992 British Crime Survey, Home Office Research Study, no. 134, HMSO, London.

Tanton, R. and Jones, R. (2003) Australian victims' propensity to report assault and break and enter to police. Paper Presented at the Evaluation in Crime and Justice: Trends and Methods Conference, Canberra, Australia.

Weber, M. (1922) Über einige Kategorien der verstehenden Soziologie. Gesammelte Aufsätze zur Wissenschaftslehre (Verlag von J. C. B. Mohr (Paul Siebeck), Tübingen, 1922), Pp. 473.

(1947) The Theory of Social and Economic Organization. Translated by A. M. Henderson and Talcott Parsons, New York: Oxford University Press, Pp. 113.

Waller, I. (1984) "Victimization surveys and public policy", in Victimization and Fear of Crime: World Perspectives: Bureau of Justice Statistics Special Report NCJ-93872, ed. R. Block, US Government Printing Office, Washington DC.

Zawitz, M.W., Klaus, P.A., Bachman, R., Bastian, L.D., DeBerry, M.M., Rand, M.R. and Taylor, B.M. (1993) High- lights from 20 Years of Surveying Crime Victims. The National Crime Victimization Survey, 1973-92, Bureau of Justice Statistics Special Report NCJ-144525. US Government Printing Office, Washington DC.

Ziehgenhagen, E. (1976) "The recidivist victim of violent crime", Victimology: An International Journal, 1: 538-50. 